\title{
In situ origin of deep rooting lineages of mitochondrial Macrohaplogroup ' $M$ ' in India
}

\author{
Kumarasamy Thangaraj ${ }^{* 11}$, Gyaneshwer Chaubey ${ }^{\dagger 1,2}$, Vijay Kumar Singh ${ }^{1}$, \\ Ayyasamy Vanniarajan ${ }^{1}$, Ismail Thanseem ${ }^{1}$, Alla G Reddy ${ }^{1}$ and Lalji Singh*1
}

Address: ${ }^{1}$ Centre for Cellular and Molecular Biology, Hyderabad-500 007, India and ${ }^{2}$ Department of Evolutionary Biology, Institute of Molecular and Cell Biology, University of Tartu and Estonian Biocentre, Tartu, Estonia

Email: Kumarasamy Thangaraj* - thangs@ccmb.res.in; Gyaneshwer Chaubey - gyanc@ebc.ee; Vijay Kumar Singh - vijays@ccmb.res.in; Ayyasamy Vanniarajan - avrajan@ccmb.res.in; Ismail Thanseem - thanzim@ccmb.res.in; Alla G Reddy - agreddy@ccmb.res.in; Lalji Singh* - lalji@ccmb.res.in

* Corresponding authors †Equal contributors

Published: 15 June 2006

BMC Genomics 2006, 7:151 doi:10.1|86/|47|-2|64-7-|5|
Received: 10 December 2005

Accepted: 15 June 2006

This article is available from: http://www.biomedcentral.com/I47|-2164/7//5 I

(c) 2006 Thangaraj et al; licensee BioMed Central Ltd.

This is an Open Access article distributed under the terms of the Creative Commons Attribution License (http://creativecommons.org/licenses/by/2.0), which permits unrestricted use, distribution, and reproduction in any medium, provided the original work is properly cited.

\begin{abstract}
Background: Macrohaplogroups ' $\mathrm{M}$ ' and ' $\mathrm{N}$ ' have evolved almost in parallel from a founder haplogroup L3. Macrohaplogroup N in India has already been defined in previous studies and recently the macrohaplogroup $M$ among the Indian populations has been characterized. In this study, we attempted to reconstruct and re-evaluate the phylogeny of Macrohaplogroup $M$, which harbors more than $60 \%$ of the Indian mtDNA lineage, and to shed light on the origin of its deep rooting haplogroups.

Results: Using II whole mtDNA and 223 I partial coding sequence of Indian M lineage selected from $8670 \mathrm{HVSI}$ sequences across India, we have reconstructed the tree including Andamanesespecific lineage $\mathrm{M} 3 \mathrm{I}$ and calculated the time depth of all the nodes. We defined one novel haplogroup M4I, and revised the classification of haplogroups M3, MI8, and M3I.

Conclusion: Our result indicates that the Indian mtDNA pool consists of several deep rooting lineages of macrohaplogroup ' $M$ ' suggesting in-situ origin of these haplogroups in South Asia, most likely in the India. These deep rooting lineages are not language specific and spread over all the language groups in India. Moreover, our reanalysis of the Andamanese-specific lineage M3I suggests population specific two clear-cut subclades (M3lal and M3la2). Onge and Jarwa share M3lal branch while $\mathrm{M} 3 \mathrm{la} 2$ clade is present in only Great Andamanese individuals. Overall our study supported the one wave, rapid dispersal theory of modern humans along the Asian coast.
\end{abstract}

\section{Background}

Variability in human mitochondrial DNA (mtDNA) offers valuable information to trace the genetic history of humans, because of the high rate of mutation and absence of recombination. Analyses of the frequency of variation and distribution of mtDNA haplogroups have been used to evaluate current models concerning the process of col- onization of world. South Asia, particularly India, lies on the path of the earliest human dispersal from Africa $[1,2]$ and hence this holds an important site of information on early human migrations.

Macrohaplogroups ' $\mathrm{M}$ ' and ' $\mathrm{N}$ ' have evolved almost in parallel from a founder haplogroup L3. A number of 
mtDNA studies based on HVS I in Indian populations have been carried out, and some information have been made available about the genetic structure of Indian gene pool [3-9]. Macrohaplogroup $\mathrm{N}$ in India has already been defined [10], and recently the macrohaplogroup $M$ among the Indian populations has also been characterized [11].

The origin of mtDNA macrohaplogroup $M$ has been an issue of controversy. Macrohaplogroup $M$ is found mainly in Asia, and its various clades makeup the great majority of Indian and Mongoloid lineages. It was hypothesized that its high frequency and diversity in Ethiopia may indicate an African origin for the entire M [14]. Nevertheless, $\mathrm{M}$ is geographically limited to Africa, while it is prevalent in Asia. If $M$ originated in Africa, then it must have occurred at an ancient time, since it had to spread throughout Asia and the New World. However, it is paradoxical that $\mathrm{M}$ crossed such a vast distance and failed to accomplish other populations of Africa, except Ethiopians and few Egyptians. The lack of time depth and classification of subhalogroups in the case of most of the lineages in the recent paper [11] tends us to reconstruct the phylogeny of macrohaplogroup $\mathrm{M}$, which harbors more than $60 \%$ of the Indian mtDNA lineage $[1,3-9]$.

\section{Results and discussion}

In this study we defined one novel haplogroup M41, and revised the classification of haplogroups M3, M18, and M31. The remaining haplogroups are also classified into subhaplogroups (M3a, M4a, M6b, M33a, M34a, M37a and M40a) by including our complete sequence information (Fig. 1 and also see Additional file 1). The geographical distributions of these samples with their haplogroup affiliation are given in Fig. 2 and the populations and their linguistic affiliations are described in Table 1.

We have revised the classification of haplogroup M3 that was previously characterized by a coding region mutation 4580 and two control region substitutions 482 and 16126. In our survey of $>5000$ samples across India, we found a considerable number of samples that have mutations at nps 482 and 16126 but don't have mutation at 4580 (our unpublished data). This suggests that 482 and 16126 are the basal mutations of this haplogroup, and 4580 might have originated later and this represent subhaplogroup M3a. Haplogroup, M18 was previously characterized by only the HVS I mutation (16318T), but now we have defined this haplogroup by two coding region mutations (12498 and 15942), and an additional control region mutation (194) (Fig. 1 and also see Additional file $1)$.

Further, we have defined several subhaplogroups based on the sharing mutations between our own and Sun et al.
[11] data [see Additional file 1]. Subhaplogroup M3a defined by a coding region mutation at 4580 , M4a defined by two coding (6620 and 7859) and three control region $(152,16145$ and 16261) mutations. Subhaplogroup M6b defined by two coding region mutations (3486 and 5585). M33a defined by two coding substitution (8562 and 15908); and M34a by six coding region (3447-8404-10361-11992-12311-14094) and three control region (146, 16095 and 16359) mutations. M37a defined by a single coding (7853) and two control region (151-152) mutations. M40a defined by a coding (13542) and three control region (200, 16179 and 16294) mutations. Interestingly, haplogroups M4, M18, M30, M37 and M38 shared a common coding region mutation (12007) from the root of haplogroup M (superhaplogroup M4'30) and later differentiated by coding and control region mutations (Fig. 1 and also see Additional file 1). We have defined one novel haplogroup, designated as M41, by six coding (870-6297-12398-12469-13656-15601) and three control $(375,16327$ and 16330$)$ region mutations with the T159 sequence of Sun et al. [11] (Fig. 1 and also see Additional file 1). M41 has also been tentatively classified in three subhaplogroups M41a, M41b and M41C. One complete sequence $\mathrm{O} 9$ from Andamanese specific haplogroup M31a has also been included here that defines subhaplogroup M31a1 by a single coding (13710) as well as a control region (200) substitution. Our reanalysis of this lineage suggests population-specific two clearcut subclades of M31a in this island. M31a1 specific mutations 200 and 13710 are exclusively present in Onge and Jarwa populations while 9617 defining M31a2 clade is present in only Greater Andamanese individuals [see Additional file 1]. All the coding region diagnostic mutations of macrohaplogroup $M$ subhaplogroups are listed in Table 2.

We have also calculated the age estimates for all $M$ branches (Fig. 1) both by using the estimated mutation calibration rate of Mishmar et al. [16], which has been recently applied in most of the mtDNA studies $[1,2,17]$, and $\rho$ (the averaged distance to a specified founder haplotype) and a mutation rate of one transition per 20,180 years between nps 16090-16365 [18]. Standard errors for coalescence time calculation were calculated following Saillard et al [19]. We found some conflict between the age estimated by both of the methods. Since, the complete sequences do not reflect the actual population size and geographical distribution, former method [18] has been used for colescent time estimation. The detailed coalescent time list is given in Additional file 2.

It is interesting to note that most of the new $\mathrm{M}$ lineages are deep rooting, and more likely arose in situ in the Indian subcontinent just after the arrival of the anatomically modern humans (Fig. 1). As shown in the figure 1, it is 


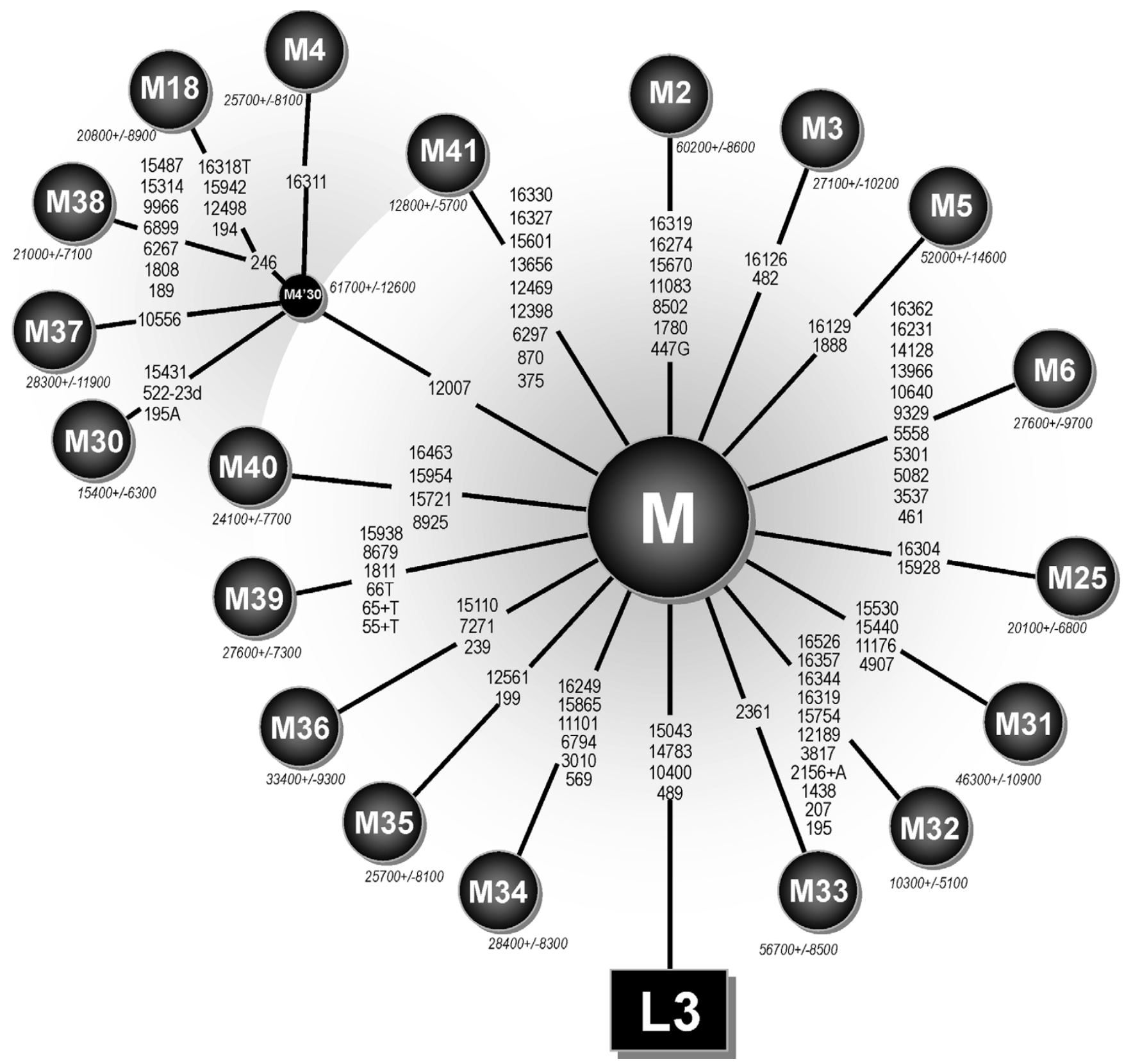

Figure I

The 'autochthonous' haplogroups of Indian macrohaplogroup M.

apparent that all the autochthonous lineages under analysis emerge directly from the root of the macrohaplogroup $\mathrm{M}$. There is no intermediate lineage shared by any two haplogroups, except for haplogroup M4'30 (Fig. 1). The star-like and non-overlapping pattern (Fig. 1) indicates that all the lineages have originated independently from the root of the macrohaplogroup $M$, thus supporting a rapid dispersal of modern humans along the Asian coast after they left Africa, followed by a long period of isolation [2].

\section{Conclusion}

In summary, based on well-resolved mtDNA macrohaplogroup $M$ phylogeny, it can be confirmed with the recent studies $[1,2]$ that a rapid dispersal of modern human took place in one wave along the Asian coast. The deep roots of $M$ phylogeny clearly ascertain the relic of Indian lineages as compared to other $M$ sub lineages suggesting 'in-situ' origin of these sub-haplogroups in South Asia, most likely in India. These deep rooting lineages are not language specific and spread over all the language groups in India. 


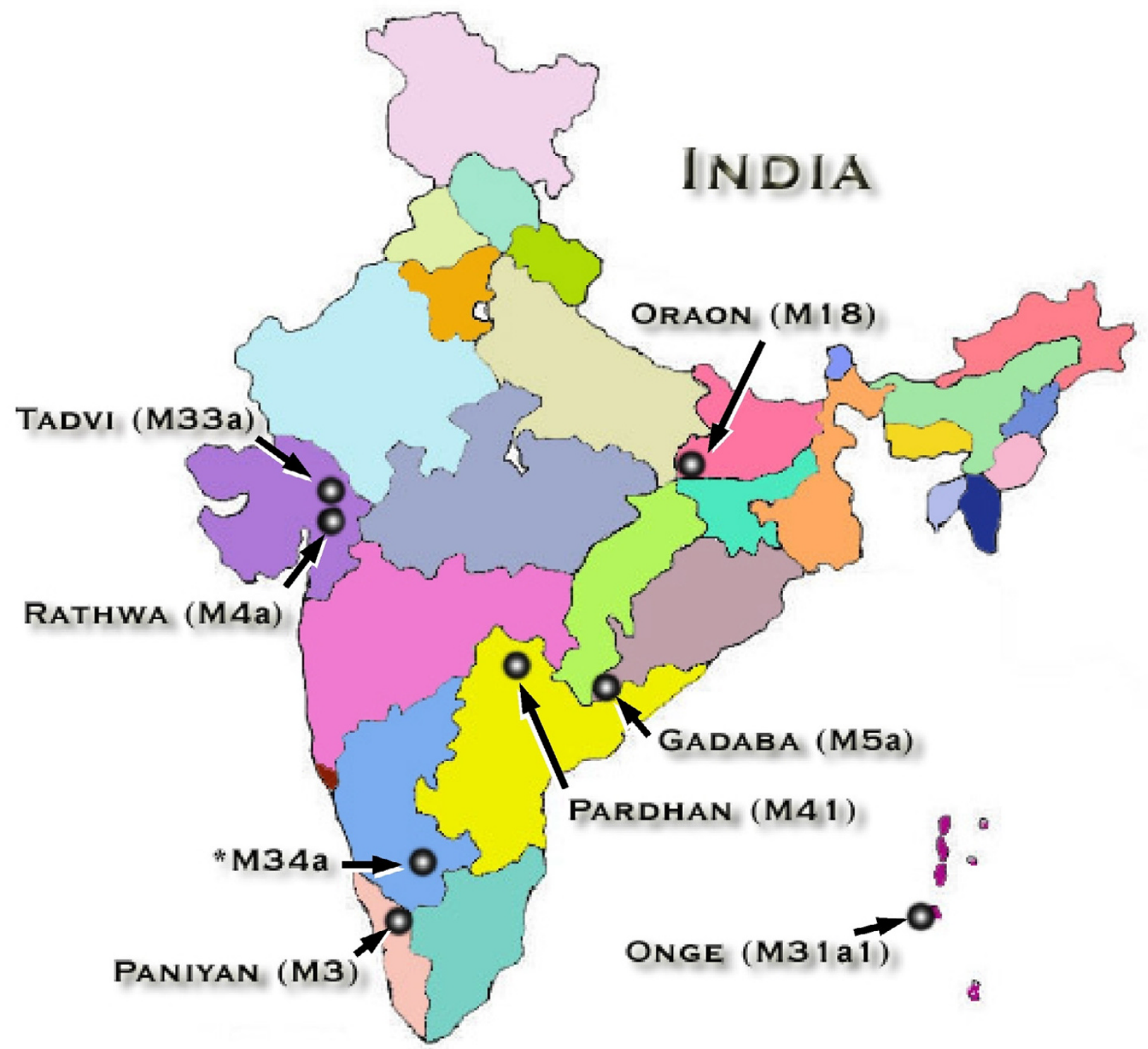

Figure 2

Geographical distribution of completely sequenced (mtDNA) samples used for the reconstruction of Indian M phylogeny. $(*)$ Random sample from Karnataka state.

Moreover, our reanalysis of Andamanese-specific lineage M31 suggests population specific two clear-cut subclades. Onge and Jarwa share M31a1 branch while M31a2 clade is present only in Great Andamanese individuals [see Additional file 1].

\section{Methods}

A phylogenetic tree reconstructed from the data of Sun et al [11] including our complete sequence information of 11 complete sequences and 2231 partial Indian samples possessing $\mathrm{M}$ selected from 8670 HVS sequences across India to resolve some of the anomalies arising due to recurrent mutations in the control region. The geographical distributions of the samples that are used for the complete sequencing of mtDNA are given in table 2 . We followed the experimental procedures, quality control measures and haplogroup nomenclature described in our previous study [1]. We have made the parsimonious tree by using our own data and data published elsewhere [11$13,15,21,22]$. The maximum parsimonious tree obtained by this procedure is shown in the figure 1 and Additional file 1. 
Table I: Samples that were sequenced for the complete mitochondrial DNA and their geographical location, linguistic affiliations and haplogroups assigned,

\begin{tabular}{|c|c|c|c|c|c|}
\hline SI. No. & Sample Code & Haplogroup & Population & Location & $\begin{array}{l}\text { Linguistic } \\
\text { Affiliation }\end{array}$ \\
\hline 1 & $\mathrm{PI} 2$ & M3 & Paniya & Kerala & Dravidian \\
\hline 2 & Or89 & M5a & Gadaba & Orrisa & Austro-Asiatic \\
\hline 3 & P3I & M6b & Paniya & Kerala & Dravidian \\
\hline 4 & T9 & M33a & Tadvi & Gujarat & Indo-European \\
\hline 5 & M42 & M34a & Random & Karnataka & Dravidian \\
\hline 6 & Or82 & MI8 & Oraon & Bihar & Austro-Asiatic \\
\hline 7 & $\mathrm{~T} 12$ & M4a & Tadvi & Gujarat & Indo-European \\
\hline 8 & $\mathrm{RI}$ & $\mathrm{M} 37 \mathrm{a}$ & Rathwa & Gujarat & Indo-European \\
\hline 9 & PS38 & M4lb & Pardhan & Andhra-Pradesh & Dravidian \\
\hline 10 & PJIO & M4lc & Pardhan & Andhra-Pradesh & Dravidian \\
\hline 11 & 09 & M3lal & Onge & Andaman & Andamanese \\
\hline
\end{tabular}

\section{Electronic database information}

Accession numbers [23] for data presented herein are as follows (for the complete mtDNA sequence accession numbers DQ408672-DQ408680 and DQ513521-
DQ513522, and for the partial region sequence accession numbers DQ653413-DQ655643).

Table 2: Coding region diagnostic mutations of Indian (mtDNA) M subhaplogroups.

\begin{tabular}{|c|c|}
\hline Haplogroups & Diagnostic coding region substitutions \\
\hline M2 & 447G-I780-8502-I I 083-15670 \\
\hline$M 2 a$ & $5252-796 \mid-8396-9758-12810$ \\
\hline M3 & 482 \\
\hline M3a & 4580 \\
\hline M4a & $6620-7859$ \\
\hline M4b & 511 \\
\hline M5 & 1888 \\
\hline M5a & $709-3921-12477-14323$ \\
\hline M6 & $46|-3537-5082-530|-5558-9329-|0640-| 3966-|4| 28$ \\
\hline M6b & $5585-3486$ \\
\hline MI8 & $12498-15942$ \\
\hline M25 & 15928 \\
\hline M30 & $1543 \mid$ \\
\hline $\mathrm{M} 30 \mathrm{a}$ & 6366 \\
\hline M30b & $5147-13980$ \\
\hline $\mathrm{M} 30 \mathrm{c}$ & 12234 \\
\hline M30d & 15259 \\
\hline M3I & $4907-1 \mid 1176-15440-15530$ \\
\hline M32 & $3817-9064-12189-15754$ \\
\hline M33 & 2361 \\
\hline M33a & $8562-15908$ \\
\hline M34 & $569-3010-6794-11101-15865$ \\
\hline M34a & $3447-8404-1036|-||992-| 23||-\mid 4094$ \\
\hline M35 & $|256|$ \\
\hline M35a & $5432-10670-15924$ \\
\hline M36 & $7271-15110$ \\
\hline M37 & 10556 \\
\hline $\mathrm{M} 37 \mathrm{a}$ & 7853 \\
\hline M38 & |808-6367-6899-9966-|53|4-|5487 \\
\hline M39 & $|8| \mid-8679-15938$ \\
\hline M40 & $8925-15721-15954$ \\
\hline $\mathrm{M} 40 \mathrm{a}$ & 13542 \\
\hline M4I & $870-6297-|2398-| 2469-|3656-| 560 \mid$ \\
\hline
\end{tabular}




\section{Competing interests}

The author(s) declare that they have no competing interests.

\section{Authors' contributions}

LS, KT, and GC conceived and designed the experiments. GC, VK, IT, AV and AGR performed the experiments and analyzed the data. LS, KT and GC wrote the paper.

\section{Additional material}

\section{Additional File 1 \\ Reconstructed phylogeny of macrohaplogroup $M$ tree by using our data and data published elsewhere [11-13,15,21,22] of Indian complete $m t D N A$ sequences. Mutations are scored after comparing with $r$-CRS [20]. Notorious mutation 16519 has been excluded from the analysis. Recurrent mutations are underlined. Suffixes are transversions. The liter- ature samples are given with the name of first author. \\ Click here for file \\ [http://www.biomedcentral.com/content/supplementary/1471- \\ 2164-7-151-S1.jpeg] \\ Additional File 2 \\ Estimated coalescent time of all the Indian M sublineages. \\ Click here for file \\ [http://www.biomedcentral.com/content/supplementary/1471- \\ 2164-7-151-S2.doc]}

\section{Acknowledgements}

We thank Mait Metspalu for help in calculating the colescent time and M.G. Palanichamy for providing his raw tree file and comments. We thank all the students and staff of various Colleges and Universities, who actively participated in this study by collecting samples from different ethnic groups of India. We are also grateful to two reviewers of this manuscript.

\section{References}

I. Thangaraj K, Chaubey G, Kivisild T, Reddy AG, Singh VK, Rasalkar AA, Singh L: Reconstructing the origin of Andaman Islanders. Science 2005, 13:996.

2. Macaulay V, Hill C, Achilli A, Rengo C, Clarke D, Meehan W, Blackburn J, Semino O, Scozzari R, Cruciani F, Taha A, Shaari NK, Raja JM, Ismail P, Zainuddin Z, Goodwin W, Bulbeck D, Bandelt HJ, Oppenheimer S, Torroni A, Richards M: Single, rapid coastal settlement of Asia revealed by analysis of complete mitochondrial genomes. Science 2005, 308: I034-1036.

3. Kivisild T, Bamshad MJ, Kaldma K, Metspalu M, Metspalu E, Reidla M, Laos S, Parik J, Watkins WS, Dixon ME, Papiha SS, Mastana SS, Mir MR, Ferak V, Villems R: Deep common ancestry of Indian and western-Eurasian mitochondrial DNA lineages. Curr Biol I999, 9:| $33 \mid-1334$.

4. Kivisild T, Rootsi S, Metspalu M, Mastana S, Kaldma K, Parik J, Metspalu E, Adojaan M, Tolk H-V, Stepanov V, Gölge M, Usanga E, Papiha SS, Cinnioglu C, King R, Cavalli-Sforza L, Underhill PA, Villems R: The genetic heritage of the earliest settlers persists both in Indian tribal and caste populations. Am J Hum Genet 2003, 72:313-332.

5. Bamshad M, Kivisild T, Watkins WS, Dixon ME, Ricker CE, Rao BB, Naidu JM, Prasad BV, Reddy PG, Rasanayagam A, Papiha SS, Villems R, Redd AJ, Hammer MF, Nguyen SV, Carroll ML, Batzer MA, Jorde LB: Genetic evidence on the origins of Indian caste populations. Genome Res 2001, I I:994-1004.

6. Metspalu M, Kivisild T, Metspalu E, Parik J, Hudjashov G, Kaldma K, Serk P, Karmín M, Behar DM, Gilbert MT, Endicott P, Mastana S,
Papiha SS, Skorecki K, Torroni A, Villems R: Most of the extant mtDNA boundaries in south and southwest Asia were likely shaped during the initial settlement of Eurasia by anatomically modern human. BMC Genet 2004, 5:26-50.

7. Thangaraj K, Sridhar V, Kivisild T, Reddy AG, Chaubey G, Singh VK, Kaur S, Agarawal P, Rai A, Gupta J, Mallick CB, Kumar N, Velavan TP, Suganthan R, Udaykumar D, Kumar R, Mishra R, Khan A, Annapurna $C$, Singh L: Different population histories of the Mundari- and Mon-Khmer-speaking Austro-Asiatic tribes inferred from the mtDNA 9-bp deletion/insertion polymorphism in Indian populations. Hum Genet 2005, I I 6:507-5 I7.

8. Kivisild T, Papiha SS, Rootsi S, Parik J, Kaldma K, Reidla M, Laos S, Metspalu M, Pielberg G, Adojaan M, Metspalu E, Mastana SS, Wang Y, Golge M, Demirtas H, Schnakenberg E, de Stefano GF, Geberhiwot T, Claustresm M, Villems R: An Indian Ancestry: a key for understanding human diversity in Europe and beyond. In Archaeogenetics: DNA and the population prehistory of Europe Edited by: Renfrew C, Boyle K. Cambridge: McDonald Institute for Archaeological Research University of Cambridge; 2000:267-279.

9. Basu A, Mukherjee N, Roy S, Sengupta S, Banerjee S, Chakraborty M, Dey B, Roy M, Roy B, Bhattacharyya NP, Roychoudhury S, Majumder PP: Ethnic India: a genomic view, with special reference to peopling and structure. Genome Res 2003, I3:2277-2290.

10. Palanichamy MG, Sun C, Agrawal S, Bandelt HJ, Kong QP, Khan F, Wang CY, Chaudhuri TK, Palla V, Zhang YP: Phylogeny of mitochondrial DNA macrohaplogroup $\mathbf{N}$ in India, based on complete sequencing: implications for the peopling of South Asia. Am J Hum Genet 2004, 75:966-978.

II. Sun C, Kong Q-P, Palanichamy MG, Agrawal S, Bandelt H-J, Yao Y-G, Khan F, Zhu C-L, Chaudhuri TK, Zhang Y-P: The dazzling array of basal branches in the mtDNA macrohaplogroup $M$ from India as inferred from complete genomes. Mol Biol Evol 2006, 3:683-690.

12. Palanichamy MG, Agrawal S, Yao Y-G, Kong Q-P, Sun C, Khan F, Chaudhuri TK, Zhang Y-P: Comment on 'Reconstructing the origin of Andaman islanders'. Science 2006, 3 I I:470a.

13. Ingman M, Gyllensten U: Mitochondrial genome variation and evolutionary history of Australian and New Guinean aborigines. Genome Res 2003, 13:1600-1606.

14. Quintana-Murci L, Semino O, Bandelt H-J, Passarino G, McElreavey K, Santachiara-Benerecetti AS: Genetic evidence of an early exit of Homo sapiens sapiens from Africa through eastern Africa. Nat Genet 1999, 23(4):437-44I.

15. Rajkumar R, Banerjee J, Gunturi HB, Trivedi R, Kashyap VK: Phylogeny and antiquity of $M$ macrohaplogroup inferred from complete mtDNA sequence of Indian specific lineages. BMC Evol Biol 2005, 5:26-33.

16. Mishmar D, Ruiz-Pesini E, Golik P, Macaulay V, Clark AG, Hosseini S, Brandon M, Easley K, Chen E, Brown MD, Sukernik RI, Olckers A, Wallace DC: Natural selection shaped regional mtDNA variation in humans. Proc Natl Acad Sci USA 2003, 100: I7I-I76.

17. Merriwether DA, Hodgson JA, Friedlaender FR, Allaby R, Cerchio S, Koki G, Friedlaender JS: Related Ancient mitochondrial $M$ haplogroups identified in the Southwest Pacific. Proc Natl Acad Sci USA 2005, I 02: I3034-13039.

18. Forster P, Harding R, Torroni A, Bandelt $\mathrm{H}-\mathrm{J}$ : Origin and evolution of Native American mtDNA variation: a reappraisal. Am J Hum Genet 1996, 59:935-945.

19. Saillard J, Forster P, Lynnerup N, Bandelt H-J, Nørby S: mtDNA variation among Greenland Eskimos: the edge of the Beringian expansion. Am J Hum Genet 2000, 67:718-726.

20. Andrews RM, Kubacka I, Chinnery PF, Lightowlers RN, Turnbull DM, Howell N: Reanalysis and revision of the Cambridge reference sequence for human mitochondrial DNA. Nat Genet 1999, 23:147.

21. Kivisild T, Shen P, Wall DP, Do B, Sung R, Davis K, Passarino G, Underhill PA, Scharfe C, Torroni A, Scozzari R, Modiano D, Coppa A, de Knijff P, Feldman M, Cavalli-Sforza LL, Oefner PJ: The role of selection in the evolution of human mitochondrial genomes. Genetics 2006, I 72:373-387.

22. Maca-Meyer N, Gonzalez AM, Larruga JM, Flores C, Cabrera VM: Major genomic mitochondrial lineages delineate early human expansions. BMC Genet 200I, 2:13-20.

23. GenBank [http://www.ncbi.nlm.nih.gov/Genbank/] 